\title{
Factors That Affect Attitude towards Generic Drugs' Prescription: A Comparison of Pakistani and Slovenian General Practitioners Practices
}

\author{
Sohail Raza* and S. M. Shafi Azam \\ sohail.raza@gmail.com \\ SZABIST \\ Karachi, Pakistan
}

\begin{abstract}
Doctors are usually concerned about the quality of generic drugs, and possible liabilities connected with their use. Therefore, this study is an attempt to examine the attitudes of Pakistani General Practitioners (GPs) towards generic prescribing drugs. This study focuses five areas that affect GPs prescribing habit of generic drugs. Moreover, this study evaluates and compares practices of GPs' towards prescribe generic drugs in Pakistan and Slovenia. 50 General Practitioners are selected from Karachi through simple random sampling. Questionnairea primary data collection tool is used to collect data from all General Practitioners. The Slovenian study is used as secondary data source. MEGASTAT-a statistical package is used to conduct chi-square test of independence at 5\% significance level. This study concludes that more academic details of generic drugs influence General Practitioners to prescribe them.
\end{abstract}

Keywords: Pharmaceutical, generic drugs, doctors, general practitioner

\section{INTRODUCTION / BACKGROUND}

Generics drugs, in general, are pharmaceutical products usually intended to be exchangeable with the research drugs, marketed after the expiry of patent or other exclusivity rights and usually manufactured without a license from the innovator company. This large category includes pharmaceuticals that were formerly patent protected, but whose patent has expired [1].

Pakistani pharmaceutical industry growing at rapid pace over last many years reached to Rs. 86 billion in 2007; in this growth, major chunk came from generic drugs manufacturer or generic drugs in Pakistan. Generic drugs in Pakistan continuously increased over the years, reached to $49.07 \%$ market share, and are likely to cross $50 \%$ market by the end of this year. While looking at the research, drugs market share in Pakistan is continuously decreasing compared to the local / generic drugs making companies in Pakistan, from 53\% to 50\% market share in year 2007 [2].
In Pakistan, many generic drugs launched before the launch of originator "innovator medicine"; like Lowplat launched by PharmEvo, generic version of Sanofi-Aventis Plavix, Hilton Pharma launched Piozer, generic version of Actos by Eli Lilly; Hilton also launched Lefora, generic version of Sanofi-Aventis Arava. In other cases, just after launch of original brand or after few new years, branded drugs were launched.

Total 106,463 of doctors registered at Pakistan Medical \& Dental Association (PMDC) up to June 2007, registered as Registered Medical Practitioners (RMP), practicing at different places under different capacities [3]. General practitioners contributed $60 \%$ of all prescription in Pakistan, while doctors working under hospital environment contribute $30 \%$ of prescription \& consultants contribute $10 \%$ of all prescriptions in Pakistan [4].

Healthcare organizations find a further way to reduce drug costs is to encourage the prescribing physicians to change their behavior. Roughly, every other physician prescribes both types of drugs, with some preferring generics and other branded products [5], [6]. Even in the absence of sound clinical research evidence, physicians usually yield to marketing pressure from the pharmaceutical industry [7].

Fewer interventions have successfully encouraged physicians to modify their prescribing practice [8], [9]. Prescribing generic drugs is one of the most frequently used prescribing indicators in General Practitioners segment in many countries [10]; also in third world countries like Pakistan, India, Bangladesh and Srilanka.

Analyzing the attitude of GPs towards generic drugs in Spain, about generic drugs, their prescribing habits, and the impact of prescribing generic drugs on health expenditure; and what they thought a generic drug should be [11]. Another one is from Slovenia surveyed 200 GPs out of 800 GPs from the National Health Insurance Institute database [12]. In Slovenia, generics command $45 \%$ market share, same as of Pakistan market share of generic drugs, continuously increasing reach to $49 \%$.

\footnotetext{
${ }^{*}$ Working at Coats Pakistan \& student of MS (MS) at SZABIST Journal of Independent Studies and Research (JISR) - Management and Social Sciences \& Economics Volume 6, Number 2, July 2008
} 


\section{OBJECTIVE OF STUDY}

General Practitioners are usually concerned about the quality of generic drugs, and possible liabilities associated with their use, despite of the healthcare professionals. Therefore, we wanted to examine the attitudes of Pakistani GPs towards generic prescribing. The findings should enable us to know the exact reasoning of GP attitude towards generic drugs prescription and compare research finding the other studies conducted in other parts of the world.

\section{PROBLEM STATEMENT}

To find out the practice of Pakistani General Practitioners towards prescribing generic drugs, and compare it with general practitioners attitude in other parts of the world.

\subsection{Research Hypothesis}

$H_{01}$ : There is no difference between doctors' prescription and patient demand for drugs in both countries

$\mathrm{H}_{\mathrm{A} 1}$ : There is difference between doctors' prescription and patient demand for drugs in both countries

$H_{02}$ : There is no difference between sources of information on drugs in both countries

$\mathrm{H}_{\mathrm{A} 2}$ : There is no difference between sources of information on drugs in both countries

$H_{03}$ : In both countries, GPs are used to prescribe generic drugs under same condition to the original one

$\mathrm{H}_{\mathrm{A} 3}$ : In both countries, GPs are used to prescribe generic drugs under different condition to the original one

$\mathbf{H}_{04}$ : Pharmaceutical companies influence General Practitioner for prescribing generic drugs in similar manners

$\mathrm{H}_{\mathrm{A} 4}$ : Pharmaceutical companies influence General Practitioner for prescribing generic drugs in different manners

$\mathbf{H}_{05}$ : Pharmaceutical companies provide unbiased data about drugs in both countries in similar way

$\mathrm{H}_{\mathrm{A} 5}$ : Pharmaceutical companies do not provide unbiased data about drugs in both countries in similar way

\section{RESEARCH METHODOLOGY}

A questionnaire is designed to ask questions about their knowledge regarding generic drugs, awareness of prescribing costs, price of generic drugs relative to branded drugs and attitude towards use of generic drugs.

Total sample size is 50 General Practitioners, selected on random basis from F. B. Area, Gulberg, Garden, Korangi, Gulshan-e-Hadeed, Landhi, Nazimabad, Orangi, Malir, Liaqatabad, P.E.C.H.S, Saddar, Gulshan-e-Iqbal, Gulistan-e-Jouhar, Defence, Kharadar \& Baldia.

We have used MEGASTAT statistical software to analyze data collected through questionnaire and compare it with Slovenian study. Inferential Statistics used \& Chisquared test done for group comparison at significance of 0.05 .

\section{DATA ANALYSIS}

a) Patient's demands for drugs by defined drug name

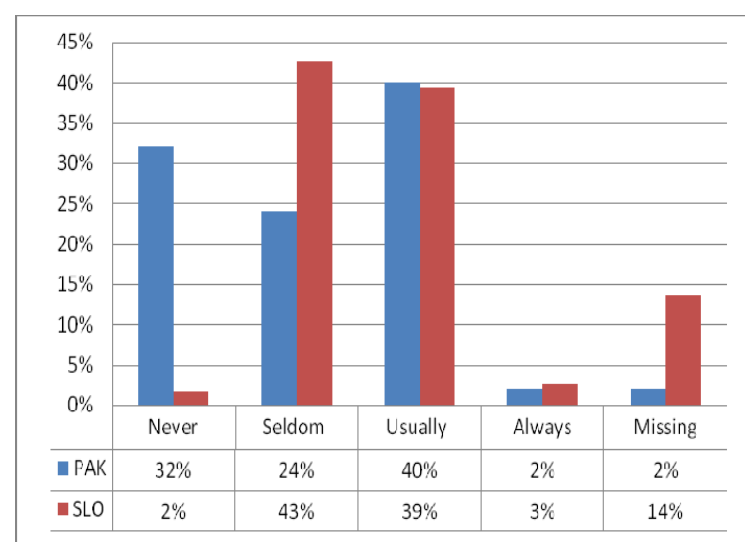

$\mathrm{H}_{01}$ : There is no difference between doctors' prescription and patient demand for drugs in both countries

$\mathrm{H}_{\mathrm{A} 1}$ : There is difference between doctors' prescription and patient demand for drugs in both countries

Table 1

\begin{tabular}{|l|c|c|c|}
\hline & PAK & SLO & Total \\
\hline Never & $32(16.85)$ & $2(16.85)$ & 34 \\
\hline Seldom & $24(33.37)$ & $43(33.37)$ & 67 \\
\hline Usually & $40(39.66)$ & $39(39.66)$ & 79 \\
\hline Always & $2(2.28)$ & $3(2.28)$ & 5 \\
\hline Missing & $2(7.84)$ & $14(7.84)$ & 16 \\
\hline
\end{tabular}

Journal of Independent Studies and Research (JISR) - Management and Social Sciences \& Economics Volume 6, Number 2, July 2008 


Total
Tource: This study

$\begin{aligned} 41.25 & \text { Chi-square } \\ 4 & \text { df } \\ 2.39 \mathrm{E}-08 & \text { p-value } \\ 9.488 & \text { Tabulated Value }\end{aligned}$

In this case, we reject Ho because Chi-square calculated 41.25 is greater than tabulated value of ChiSquare 9.488 in both countries, usually not followed patient's demands for drugs by defined drug name.

Above graph clearly shows that Pakistani GPs not followed the patient's demands for drugs by defined drug name, as 32\% of GPs responded; while in case of Slovene General Practitioners, only 2\% of GPs agreed that they never followed the patient's demand of drug by name. Moreover, in case of seldom, 43\% Slovenian General Practitioners seldom followed the patient's demands of drug by name in case of this statistics, becomes $24 \%$.

\section{b) Where do patients get information on drugs}

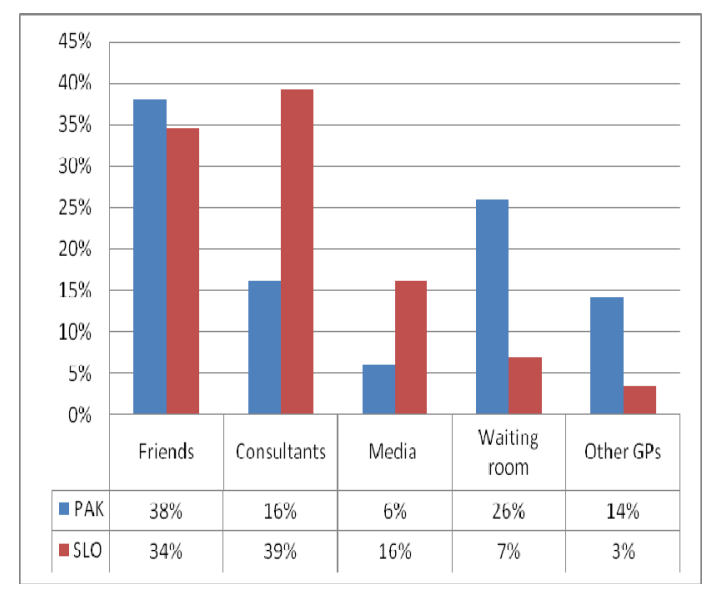

$\mathrm{H}_{02}$ : There is no difference between sources of information on drugs in both countries

$\mathrm{H}_{\mathrm{A} 2}$ : There is no difference between sources of information on drugs in both countries

Table 2

\begin{tabular}{|l|c|c|c|}
\hline & PAK & SLO & Total \\
\hline Friends & $38(36.24)$ & $34(36.24)$ & 72 \\
\hline Consultants & $16(27.54)$ & $39(27.54)$ & 55 \\
\hline Media & $6(11.05)$ & $16(11.05)$ & 22 \\
\hline
\end{tabular}

\begin{tabular}{|l|c|c|c|}
$\begin{array}{l}\text { Waiting } \\
\text { room }\end{array}$ & $26(16.45)$ & $7(16.45)$ & 33 \\
\hline Other GPs & $14(8.72)$ & $3(8.72)$ & 17 \\
\hline Total & 100 & 100 & 200 \\
\hline
\end{tabular}

Source: This study

$$
\begin{array}{rl}
31.93 & \text { Chi-square } \\
4 & \mathrm{df} \\
1.98 \mathrm{E}-06 & \mathrm{p} \text {-value } \\
9.488 & \text { Tabulated Value }
\end{array}
$$

In this case, we reject Ho because Chi-square calculated 31.93 is greater than tabulated value of ChiSquare 9.488 in both countries, in both countries patients are not getting information on drug from same source.

This graph also depicts that in Slovenia, patients are getting information mainly from their consultants and their friends (34\% \& 39\% respectively); while in case of Pakistan, patients are getting information from their friends and waiting room at the General Practitioners Clinics (38\% \& 26 \& respectively).

In case of other factors of information, from consultants $16 \%$; media only $6 \%$, as in Pakistan advertising on media is ban by the Ministry of Health for Ethical Drugs (Prescription Drugs that are prescribed by the doctors only); and from other GPs, $14 \%$ of patients are getting information about the drugs.

c) Condition in which GPs prefer to prescribing generic drugs

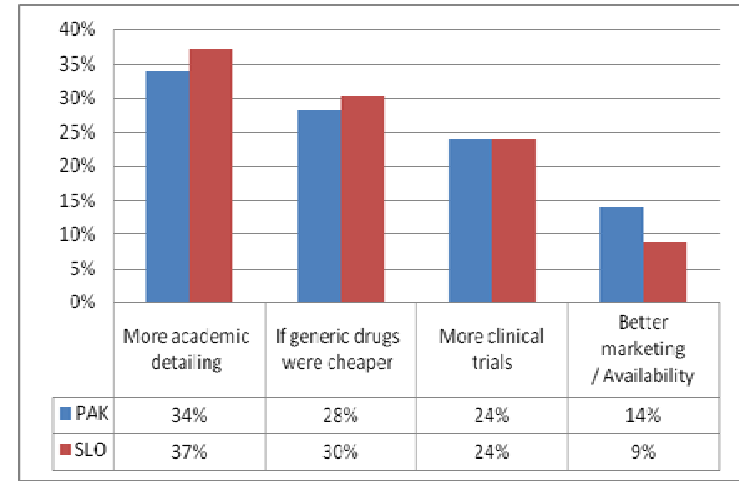

$H_{03}$ : In both countries, GPs are used to prescribe generic drugs under same condition to the original one

$\mathrm{H}_{\mathrm{A} 3}$ : In both countries, GPs are used to prescribe generic drugs under different condition to the original one

Journal of Independent Studies and Research (JISR) - Management and Social Sciences \& Economics Volume 6, Number 2, July 2008 
Table 3

\begin{tabular}{|l|c|c|c|}
\hline & PAK & SLO & Total \\
\hline $\begin{array}{l}\text { More } \\
\text { academic } \\
\text { detailing }\end{array}$ & $34(35.49)$ & $37(35.49)$ & 71 \\
\hline $\begin{array}{l}\text { If generic } \\
\text { drugs were } \\
\text { cheaper }\end{array}$ & $28(29.10)$ & $30(29.10)$ & 58 \\
\hline $\begin{array}{l}\text { More clinical } \\
\text { trials }\end{array}$ & $24(23.98)$ & $24(23.98)$ & 48 \\
\hline $\begin{array}{l}\text { Better } \\
\text { marketing / } \\
\text { availability }\end{array}$ & $14(11.43)$ & $9(11.43)$ & 23 \\
\hline Total & 100 & 100 & 200 \\
\hline
\end{tabular}

Source: This study

$\begin{aligned} 1.37 & \text { Chi-square } \\ 3 & \text { df } \\ .7132 & \text { p-value } \\ 7.815 & \text { Tabulated Value }\end{aligned}$

In this particular case, we accept Ho because ChiSquare calculated 1.37 is less than tabulated value of ChiSquare 7.815, means that in both countries, GPs used to prescribe generic drugs under same condition to the original one.

In both countries, general practitioners rated more to more academic detailing of the drugs (37\% in case of Slovenia \& 34\% in case of Pakistan), second highest rated factor in prescribing generic drugs. If generic drugs were cheaper (30\% \& 28\% respectively), followed by more clinical trial of these drugs conducted in the country (24\% in both cases) lowest rated factors is the better marketing / availability of generic doctors ( $9 \%$ \& 14\%) compared to Slovenia, rated more to this particular factor.

\section{d) Pharmaceutical companies influence in prescribing generic drugs}

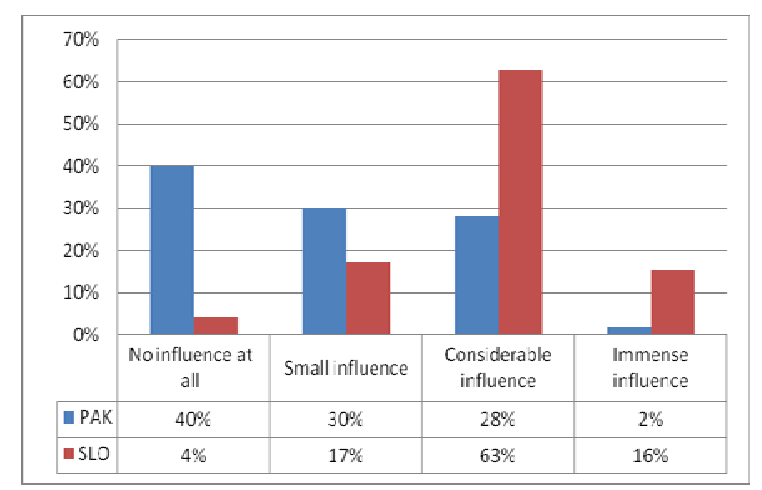

$\mathrm{H}_{04}$ : Pharmaceutical companies influence General Practitioner for prescribing generic drugs in similar manners

$\mathrm{H}_{\mathrm{A} 4}$ : Pharmaceutical companies influence General Practitioner for prescribing generic drugs in different manners

Table 4

\begin{tabular}{|l|c|c|c|}
\hline & PAK & SLO & Total \\
\hline $\begin{array}{l}\text { No influence } \\
\text { at all }\end{array}$ & $40(22.16)$ & $4(22.16)$ & 44 \\
\hline $\begin{array}{l}\text { Small } \\
\text { influence }\end{array}$ & $30(23.62)$ & $17(23.62)$ & 47 \\
\hline $\begin{array}{l}\text { Considerable } \\
\text { influence }\end{array}$ & $28(45.47)$ & $63(45.47)$ & 91 \\
\hline $\begin{array}{l}\text { Immense } \\
\text { influence }\end{array}$ & $2(8.76)$ & $16(8.76)$ & 18 \\
\hline Total & 100 & 100 & 200 \\
\hline
\end{tabular}

Source: This study

$\begin{array}{rl}56.04 & \text { Chi-square } \\ 3 & \mathrm{df} \\ 4.12 \mathrm{E}-12 & \mathrm{p} \text {-value } \\ 7.815 & \text { Tabulated Value }\end{array}$

In this particular case, we reject Ho because ChiSquare calculated 56.04 is greater than tabulated value of Chi-Square 7.815, means both countries pharmaceutical companies influence General Practitioner for prescribing generic drugs in different manners.

In case of Pakistan, major General Practitioner was of the opinion that pharmaceutical companies do not influence, at all, to prescribe generic drugs, $40 \%$ compare to Slovenian case only 4\%; while in case of small influence, $30 \%$ of GPs agreed that some companies, but small, influence in prescribing drugs. Moreover, Slovenian case major GPs (63\% of sample) agreed that pharmaceutical companies, but considerable, influence on GPs to prescribe the generic drugs.

\section{e) Unbiased data about drugs}

Journal of Independent Studies and Research (JISR) - Management and Social Sciences \& Economics Volume 6, Number 2, July 2008 


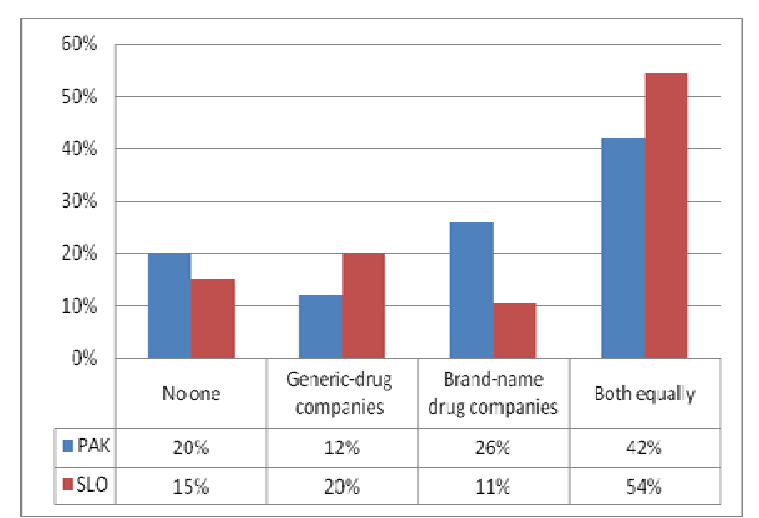

\section{$\mathbf{H}_{05}$ : Pharmaceutical companies provide unbiased data about drugs in both countries in similar way}

$\mathrm{H}_{\mathrm{A} 5}$ : Pharmaceutical companies do not provide unbiased data about drugs in both countries in similar way

Table 5

\begin{tabular}{|l|c|c|c|}
\hline & PAK & SLO & Total \\
\hline No one & $20(17.46)$ & $15(17.46)$ & 35 \\
\hline $\begin{array}{l}\text { Generic-drug } \\
\text { companies }\end{array}$ & $12(16.09)$ & $20(1.09)$ & 32 \\
\hline $\begin{array}{l}\text { Brand-name } \\
\text { drug companies }\end{array}$ & $26(18.26)$ & $11(18.26)$ & 37 \\
\hline Both equally & $42(48.19)$ & $54(48.19)$ & 96 \\
\hline Total & 100 & 100 & 200 \\
\hline
\end{tabular}

Source: This study

$\begin{array}{rl}10.97 & \text { Chi-square } \\ 3 & \mathrm{df} \\ .0119 & \mathrm{p} \text {-value } \\ 7.815 & \text { Tabulated Value }\end{array}$

In this case, we reject Ho because Chi-Square calculated 10.97 is greater than tabulated value 7.815.

General Practitioners in both countries agreed that both generic as well as branded "research" drug companies provide unbiased data of their drugs (42\% in Pakistan \& 54\% Slovenian), In Pakistan, 26\% of GPs was of opinion that branded name drug companies provide unbiased, compared to only $11 \%$ in Slovenian.

\section{CONCLUSION}

This study is an attempt to evaluate practice of General Practitioner to prescribe generic drugs in Pakistan and Slovenia. This study focuses five different areas, which influence doctors' prescribing habit of generic drugs.

This research concludes that only a single area has similar practice between both countries, that is, General Practitioners preference to prescribe generic drugs is followed by details that are more academic.

In addition to above, generic drugs companies also conducted local trial of their drugs at private clinics / hospital level to show the effectiveness of their drugs, compared to the original drugs. Moreover, doctors rated better marketing/availability of the drugs at a lower scale.

Pharmaceutical companies in Slovenia put more pressure on the General Practitioner to prescribe the generic drugs.

As far as information provided by the pharmaceutical companies to the doctors, they agreed, in both countries, that both brand drugs as well as generic companies, provide unbiased data about drugs.

\section{RECOMMENDATIONS}

1. Major reason why GPs are ready to use generic drugs is the price difference between original drugs compared to generic drugs, so generic companies have to offer economical prices to doctors along with quality medicine.

2. Generic drugs companies have to make sure that they always used unbiased data for their drugs, that is not only beneficial for drugs but also position company as ethical company that always follow of pharmaceutical industry / medicine ethics for promoting their drugs to the doctors.

3. In Pakistan, many people used to take drugs without concerning any doctors, because people living around them used to give them advice to use particular drugs for particular illness, as they also had these drugs in past to treat their illness. Here, Ministry of Health's role comes in; they have to restrict pharmacies for not providing any drugs without doctor's prescription, as it is a practice in European countries as well as in North America. Only, Over the Counter (OTC) drug is allowed to the patient without having any prescription, as OTC already passed safety criteria of $\mathrm{MOH}$.

4. Nowadays, generic drugs companies also conduct local trial of their drugs at doctors / hospital level to show the effectiveness of their drugs compared to the original drugs, resulting an increase in the confidence of the doctors to prescribe the generic drugs to their patients in many diseases. Even

Journal of Independent Studies and Research (JISR) - Management and Social Sciences \& Economics Volume 6, Number 2, July 2008 
now, doctors are prescribing generic version of drugs in chronic disease, as well, they have to increase this practice.

5. As far as information provided by the pharmaceutical companies, the doctors agreed in both countries that, both, brand drugs as well as generic companies provide unbiased data about drugs, most of the times to doctors. While, in case of Pakistan, General Practitioner rated branded drugs companies more than generic; while in case of Slovenia, General Practitioner are on greater extend agreed to Generic drugs companies which provide unbiased data on their drugs. All pharmaceutical companies, especially generic drugs companies, make sure that whatever information is provided to doctors must be supported by the valid source, so that anyone in healthcare can check, it if they want.

\section{REFERENCES}

[1] World Health Organization, The World Medicines Situation, The World Medicines Situation, 2004, 37.

[2] IMS Health Pakistan, "Pakistan Pharmaceutical Index", IMS Health Pakistan, Q2 2007.

[3] PMDC: Total number of doctors / dental surgeons (GP's) registered up to $30^{\text {th }}$ June 2007.

[4] Hasnain, Raza, interview by Sohail Raza, Business Unit Manager - Roche (October 10, 2007).

[5] JK, Hellerstein, "The importance of the physician in the generic versus trade-name prescription decision", The Rand Journal of Economics, 1998: 29, 108-136.

[6] Himmel W, Kron M, Thies-Zajonc S, Kochen MM., "Changes in drug prescribing under the Public Health Reform Law-A survey of general practitioners' attitudes in East and West Germany", International Journal of Clinical Pharmacology and Therapeutics, 1997: 35, 164-169.

[7] Mintzes B, Barer ML, Kravitz RL et al., "How does Direct-To-Consumer Advertising (DTCA) affect prescribing? A survey in primary care environments with and without legal DTCA" CMAJ, 2003: 169, 405-412.

[8] Mukamal KJ, Markson LJ, Flier SR, Calabrese D. "Restocking the sample closet: results of a trial to alter medication prescribing", Journal of the American Board of Family Practice, 2002: 15, 285-289.
[9] Bloor K, Freemantle N., "Fortnightly Review: Lessons from international experience in controlling pharmaceutical expenditure II: influencing doctors", BMJ, 1996: 312, 1525-1527.

[10] Williams D, Bennett K, Feely J., "The application of prescribing indicators to a primary care prescription database in Ireland", European Journal of Clinical Pharmacology, 2005: 61, 127-133.

[11] Garcia AJ, Martos F, Leiva F et al., "Genéricos: Buenos o malos? Conocimientos y actitudes de los medicos ante los medicamentos genéricos", Gaceta Sanitaria, 2003: 17, 144-149.

[12] J. Kersnik, J. Peklar MR Pharm., "Attitudes of Slovene general practitioners towards generic drug prescribing and comparison with international studies", Journal of Clinical Pharmacy and Therapeutics, 2006: 31, 577-583.

Journal of Independent Studies and Research (JISR) - Management and Social Sciences \& Economics Volume 6, Number 2, July 2008 